\title{
Dinâmicas de Gênero e Sexualidade no Sexo Tarifado entre Homens: Uma Análise por Meio da Noção de Comunidades de Prática
}

\author{
Cristiano Hamann ${ }^{1}$ \\ Programa de Pós-Graduação em Psicologia Social e Institucional da Universidade Federal \\ do Rio Grande do Sul, Porto Alegre, RS, Brasil \\ Adolfo Pizzinato \\ Kátia Bones Rocha \\ Pontifícia Universidade Católica do Rio Grande do Sul, Porto Alegre, RS, Brasil
}

\begin{abstract}
Resumo
Este estudo analisa a constituição de comunidades de prática no contexto do sexo tarifado exercido por homens, com foco nos exercícios de sexualidade e identificações de gênero. Utilizou-se de uma abordagem inspirada na Teoria Fundamentada, por meio da qual se realizaram diários de campo das incursões em ambientes de sexo tarifado, entrevistas narrativas com seis homens que se dedicam a atividade e dois gerentes de duas casas especializadas no mercado de sexo porto-alegrense, durante o ano de 2015. $\mathrm{O}$ corpus foi analisado discursivamente e identificaram-se dinâmicas associadas à formação de comunidades de prática pela via de estratégias de vigilância e correção, de modo que aspectos como o investimento corporal e outras dimensões performativas atualizavam relações de consumo circunscritas em algumas esferas de controle. Exercício de poder se mostram pela via da "dessexualização" do cliente, ou da feminilização do garoto de programa, indicando que a noção de comunidade não se dissociava de aspectos discursivos heteronormativos.
\end{abstract}

Palavras-chave: Gênero, sexualidade, prostituição, homens.

\section{Gender and Sexuality Dynamics in Tariffed Sex among Men: Analysis of the Notion of Communities of Practice}

\begin{abstract}
The present study analyzes the establishment of communities of practice in the context of tariffed sex exercised by men, focusing on sexuality performances and gender identifications. Was used an approach inspired by the Grounded Theory, through which were held field diaries in tariffed sex settings, narrative interviews with six men who engage in the activity and two managers, respectively, of two specialized places in the Porto Alegre's sexual market, during the year 2015. The corpus was analyzed from a discursive theoretical perspective and was identified dynamics associated with the formation of communities of practice by means of surveillance and correction strategies, in a way that aspects such as corporeal and performative investment updated consumer relations circumscribed in some control dynamics. Power relations are shown in a way of "desexualization" of the client, or the feminization of the male prostitute, so the notion of community does not dissociate from discursive heteronormative aspects.
\end{abstract}

Keywords: Gender, sexuality, male prostitution, communities of practice, grounded theory.

Endereço para correspondência: Universidade Federal do Rio Grande do Sul, Instituto de Psicologia, Programa de Pós-Graduação em Psicologia Social e Institucional, Rua Ramiro Barcelos, 2600, Térreo, Porto Alegre, RS, Brasil 90035-003. E-mail: cristiano.hamann@gmail.com 


\section{Dinámica de Género y Sexualidad en Sexo Tarifado entre Hombres: Um Análises a través del Concepto Comunidades de Práctica}

\section{Resumen}

Este estudio analiza la formación de comunidades de práctica en el contexto del sexo tarifado ejercido por los hombres, centrándose en los ejercicios de la sexualidad y las identificaciones de género. Se utilizó un enfoque inspirado en la teoría fundamentada, a través de la cual se llevó a cabo incursiones de campo en entornos sexuales tarifados, entrevistas narrativas con seis hombres que se dedican a la actividad y dos gerentes de dos casas especializadas en el mercado del sexo durante el año 2015, en Porto Alegre (BR). El corpus ha sido analizado discursivamente e se han identificado dinámicas asociadas a la formación de comunidades de práctica por la vía de estrategias de vigilancia y corrección, de manera que aspectos como la inversión corporal y performativa actualizaban relaciones de consumo circunscriptas en dimensiones de control. Formas de relación de poder se muestran por la vía de la "desexualización" de los clientes, o la feminización del prostituto, de modo que el sentido de comunidad no se disociaba de aspectos heteronormativos.

Palabras clave: Género, sexualidad, prostitución, hombres.

Estudos que se dedicam à prostituição convidam a atentar para a diversidade de possibilidades no exercício de sexualidades, seus intrincados marcadores sociais e os discursos que compõem essa rede de sentidos atribuídos a este fazer (Piscitelli, 2014). Trata-se de um campo estratégico de discussão, visto que a prática da prostituição permite discutir uma complexa rede que envolve relações de gênero, trabalho, sexualidade, moralidade e direitos humanos (Rios, 2012). Pesquisas internacionais têm se dedicado, majoritariamente, a mapear o que definem como os riscos da prostituição, especialmente em relação à infecções sexualmente transmissíveis como HIV/AIDS - e dimensões sociodemográficas relacionadas (Baral et al., 2015).

Entretanto, mesmo o panorama de pesquisas na área que atende a essa noção de risco é heterogêneo e parte destes trabalhos indicam a complexidade do campo, para além de resultados de caráter sanitário. Ballester, Salmerón, Gil e Giménez (2014), por exemplo, atentam para o fato de que variáveis como local de origem, escolaridade e orientação sexual não são suficientes para compreender o fenômeno, ainda que sejam aspectos importantes de discussão. Pesquisas desenvolvidas no leste europeu, de outra forma, também destacam que os itinerários de prostituição vinculados a bares são relacionados a maiores vulnerabilidades, como abuso de álcool, drogas ilícitas e situações de violência do que nos negócios estabelecidos via da internet (Bar-Johnson \& Weiss, 2015; Niccolai, King, Eritsyan, Safiullina, \& Rusakova, 2013). Outro aspecto a ser considerado é a análise de risco de infecção por HIV quando se comparam as práticas sexuais com clientes e com parceiros não comerciais (Grov, Rodriguez-Díaz, Jovet-Toledo, \& Parsons, 2015).

Estudos como os já citados nos permitem identificar uma interlocução a ser investida, entre dimensões epidêmicas e considerações qualitativas e contextuais, que problematizem a complexidade que circunscreve as vivências cotidianas do sexo tarifado - e que falam sobre a necessidade de enfocar aspectos como a criminalização, trabalho, gênero e sexualidade que caracterizam possibilidades do fazer desses homens, assim como seus itinerários no comércio sexual. Alguns estudos qualitativos sobre prostituição de homens, especialmente no Brasil, têm buscado integrar os elementos psicossociais supracitados. Pesquisas de perspectiva etnográfica, por exemplo, têm possibilitado pensar a prostituição de homens em dimensões de sexualidade, subjetividade e território, indicando a particularidade de itinerários (Barreto, 2012; Viana, 2010), espaços de turismo sexual em relação aos diferentes eixos de poder que complexificam perspectivas abolicionistas sobre a prostituição 
(Cantalice, 2009) e suas vinculações com heteronormatividade e homonormatividade (Pocahy, 2012).

No Brasil, especificamente, essa maior visibilidade pode estar associada à abertura política nos Estudos de Gênero, que têm permitido compreender as pluralidades do "ser homem" na contemporaneidade e suas relações com sistemas assimétricos de poder no âmbito das relações humanas (Medrado \& Lyra, 2008; Piscitelli \& Simoni, 2015). Entretanto, o campo de discussão acerca dos meandros da prostituição está principalmente voltado para a vivência de mulheres (em especial as cisgêneras). Mesmo que a reflexão sobre as experiências de mulheres na prostituição seja estratégica, evidenciando em discursos pró e contra (Piscitelli, 2012; Melo Pedroso, 2015), cabe atentar para a posição periférica dos homens nesse campo de estudos. Considerando essa defasagem, neste artigo procura-se analisar um aspecto particular deste fenômeno: a configuração de comunidades de prática específicas de sexo tarifado de homens ${ }^{2}$ em Porto Alegre, que envolve articulações discursivas relacionadas a exercícios de sexualidade e identificações de gênero.

Alguns aspectos do contexto de prostituição de homens em Porto Alegre já foram traçados. No período de 2004 e 2005 os grupos nuances e GAPA/RS, em projeto intitulado "Prazer Também tem Preço", realizaram um levantamento em locais fechados (Bar, Sauna e Agência) da prostituição de homens na região metropolitana da cidade (Nardi, 2006). Contando com um questionário aplicado a 106 garotos e 78 clientes, e observações nos locais de prostituição, algumas questões relativas a marcadores sociais chamam a atenção. Em relação à caracterização, " $90,6 \%$ tinham entre 18 a 24 anos" (Nardi, 2006, p. 53); “70,8\% se declararam brancos" (p. 54); " $38,7 \%$

\footnotetext{
Ainda que se utilize o termo "prostituição", neste estudo compreende-se o fenômeno principalmente pela via do termo "sexo tarifado" (Pocahy, 2011). A utilização deste termo procura desestabilizar a noção de "prostituição" como vinculada a negociações exclusivamente monetárias - atentando para a pluralidade de trocas que acontecem na dinâmica em questão.
}

ensino médio completo" (p. 55). Em relação ao tempo na prostituição, " $44,3 \%$ tinham de " 1 a 5 anos de atividade" (p. 58). No que concerne aos clientes, foi percebido que " $67,9 \%$ tinham idade entre 31 e 50 anos" (p. 53); "73,1\% declaravam-se brancos" (p. 54); " $38,5 \%$ tinham ensino médio completo e $41 \%$ ensino superior completo" (p. 55).

O panorama teórico analisado, somado à caracterização deste coletivo, apontam para a necessidade dos estudos no campo das relações de gênero que se dediquem a desnaturalizar a construção de subjetividades e masculinidades nas suas relações com o sexo tarifado. No entrelaçamento de questões como subjetividade, masculinidades e sexo tarifado, parece apropriado considerar a dimensão das narrativas pessoais e os discursos vinculados à sua construção no tecido social. Nesse sentido, a linguagem torna-se central, e esta é compreendida como produtora de realidades, em que se performatizam modos de existência - um processo de repetição e regulação de atos, gestos, comportamentos que indicam possibilidades de os sujeitos ocuparem lugares legítimos ou ilegítimos no campo social - e as relações de gênero e sexualidade que fazem parte destas construções (Butler, 2002). Essas relações estão vinculadas a normas calcadas na repetição e regulação, aspectos socialmente engendrados (Foucault, 1987), cuja análise crítica dá subsídios para se compreender categorias sociais como homem/mulher, e as esferas masculino/feminino, como manifestações performativas (Butler, 2002). Assim, a sexualidade é aqui compreendida como fenômeno social (Foucault, 1988), tanto quanto o exercício de masculinidades e sua vinculação com as formas de tornar-se homem contemporaneamente (Badinter, 1993; Caetano, Silva, \& Garay-Hernández, 2015; Connell \& Messerschmidt, 2013; Kimmel, 1997; Viveros-Vigoya, 2011).

Neste campo de discussão, podemos considerar que o processo de se tornar homem ou mulher funciona por meio de "coordenadas culturais na constituição da subjetividade" (Madureira \& Branco, 2007, p. 82), de modo que está ligado às posições assumidas no panorama cultural que se dão por toda a vida (Louro, 2011). A subjeti- 
vidade é aqui compreendida por uma perspectiva sociocultural, como um processo em contínuo desenvolvimento (Kirschner, 2010) e como construção intersubjetiva que se dá também pela via da narrativa. Nestas construções que se dão de forma narrativa, gênero e sexualidade figuram com especial importância, e estes aspectos são a tônica do presente estudo. Considera-se a premissa de que existe uma organização social de poder intrínseca nestas relações (Scott, 1995), que transcende diferenciações biológicas e atenta à formação dos sujeitos pela via do poder e, portanto, na lógica oposta à naturalização/ essencialização e ao binarismo, já que estas dimensões simbólicas se configuram em contextos particulares e, portanto, mutáveis (Piscittelli \& Simoni, 2015). Gênero e sexualidade, tomados como conceitos operacionais para a contestação deste tipo de naturalização, põem em pauta questões que estão situadas na experiência cotidiana que demandam análises situadas e, portanto, parciais (Haraway, 1995). Considerando esta noção de conhecimento situado, propomos um exercício de aproximação da perspectiva de gênero e sexualidade com o modelo de comunidades de prática, tal como na análise proposta por Paechter (2003).

Segundo Wenger (2001), a noção de comunidade se organiza a partir de três eixos integrados: compromisso mútuo, ação conjunta e repertório compartilhado. Estas noções permitem que se compreenda o processo de constituição de uma comunidade como relação contextual e coerente de práticas, identificações e aprendizagens. Para Wenger (2001), esses aspectos não supõem homogeneidade, podendo compor-se numa relação de complementariedade ou de parcialidade situada. Compromisso mútuo fala de uma rede de significados que se negocia mutualmente. Baseia-se, neste sentido, num processo de fazer conjuntamente, e, portanto, na manutenção de uma comunidade pela via da relação e da negociação dos processos grupais. A segunda noção envolvida, a ideia de ação conjunta, compreende as práticas resultado da relação de responsabilidade mútua em determinada comunidade. O terceiro aspecto, entretanto, caracterizado como repertório compartilhado, compreende uma di- mensão histórica de compromisso mútuo, concebida num conjunto de aspectos como discursos compartilhados, conceitos, artefatos e estilos envolvidos nas práticas comunitárias.

Partimos, portanto, da noção de comunidades de prática como fenômeno intrinsecamente relacionado à construção e manutenção de significados e sentidos no âmbito do sexo tarifado exercido por homens, considerando que essa dimensão não se faz dissociada dos marcadores sociais de diferença e dos efeitos das configurações dos modos de vida capitalísticos (Streek, 2012) claramente implicados nesses processos. Gênero e sexualidade são interpretados como instâncias performatizáveis, que se inscrevem nos corpos, situadas e indicativas de certas ficções reguladoras (Butler, 2002), calcadas em relações de poder (Scott, 1995) e que se manifestam em processos de repetição e regulação (Foucault, 1987). Para tanto, este estudo propõe-se a analisar a esfera caracterizada como das comunidades de prática no contexto do sexo tarifado exercido por homens em Porto Alegre, em específico, analisando os aspectos comunicacionais e discursivos relacionados aos exercícios de sexualidade e identificações de gênero.

\section{Método}

O problema elencado nesta investigação ${ }^{3} \mathrm{e}$ as dimensões da realidade estudadas inscrevem este trabalho em uma abordagem qualitativa, sensível às vivências do pesquisador e às considerações trazidas por pessoas em campo. Para tanto, utilizou-se de uma abordagem inspirada na Teoria Fundamentada (Charmaz, 2009). De acordo com os pressupostos da Teoria Fundamentada, o processo de elaboração de uma pesquisa inicia-se pela formulação de questões que

3 Esta pesquisa é derivada do Projeto intitulado "Circunscritores de desejo: itinerários de homens no contexto do sexo remunerado", aprovado pelo Comitê de Ética em Pesquisa da Pontifícia Universidade Católica do Rio Grande do Sul (PUCRS), número 42022315.6.0000.5336, parecer 1.017.883. Todas as entrevistas foram realizadas com Termo de Consentimento Livre e Esclarecido. 
sejam suficientemente abertas, de modo a permitir que as interpretações empíricas deem ensejo ao direcionamento da pesquisa (Charmaz, 2009). Este método parte de uma sistemática que consiste no retorno e discussão dos objetivos da pesquisa a cada nova coleta; (re)organização constante do material coletado; codificação e categorização das informações e sistematização de resultados em memorandos.

Neste sentido, a pesquisa sofreu alterações em seu andamento, especificamente no que diz respeito a locais visitados. Os locais foram sendo acrescentados no decorrer das entrevistas realizadas, por indicações dos participantes, alargando o campo de observação e o referencial bibliográfico utilizado (que sofreu alterações ao longo do processo de contato com temáticas antes não planejadas, trazidas pelas vivências com os participantes do estudo), até que conseguiu-se uma articulação analítica de caráter teórico-vivencial que possibiltou respostas às questões aqui levantadas, especialmente no que respeita a formação de uma comunidade de práticas articulada tal como defende Wenger (2001).

Ainda que uma rede de locais tenha sido mapeada nesta pesquisa - uma rua, duas saunas, dois bares - as análises deste estudo foram desenvolvidas com base em interlocuções com homens de dois ambientes específicos em Porto Alegre: um bar e uma sauna. Esta escolha se deu por serem os locais mais frequentados pela rede de participantes da pesquisa e que aglutinavam participantes que também desenvolviam práticas em outros contextos. A coleta de dados foi realizada através de incursões nestes ambientes de sexo tarifado, trabalho de observação que ocorreu ao longo de 2015, alicerçando um diário de campo com registro descritivo, que também contou com conversas informais com pessoas nestes ambientes e entrevistas. No que concerne a entrevistas realizadas, tivemos 2 entrevistas de homens que ocupavam cargos de gerência, 4 que se dedicavam ao sexo tarifado nos ambientes supracitados e 2 outros que também se dedicavam ao sexo tarifado, mas que desenvolviam suas atividades fora do circuito alvo deste estudo (um através de aplicativos de encontro sexual e outro que atende exclusivamente clientes fixos, conquistados em seu passado na prostituição de rua). A inserção destes dois últimos participantes se deu através da indicação dos outros participantes.

Todos os entrevistados foram contatados através de um primeiro informante-chave, gestor de saúde sexual e por meio de amostragem intencional de tipo snowball (Flick, 2009). Para além das inúmeras conversas e dos diários de campo elaborados, as oito entrevistas realizadas seguiram a perspectiva narrativa. Segundo Bauer e Jovchelovitch (2002), a entrevista narrativa é uma forma de entrevista em profundidade que exige do entrevistador ter influência mínima na fala do ou da participante, de modo a não estabelecer obstáculos na história narrada. Planejar a questão gerativa ou tópico inicial que vai dar vazão à fala é um dos processos fundamentais da técnica (Bauer \& Jovchelovitch, 2002; Flick, 2009). Para esta pesquisa, a questão formulada - e que esteve sujeita a uma aproximação aos termos nativos ao longo das entrevistas - foi: "Como começou e vem se desenvolvendo a tua trajetória no contexto do sexo tarifado?". Não se estabeleceu um tempo específico de entrevista, como indicado em literatura especializada (Bauer \& Jovchelovitch, 2002; Flick, 2009), entretanto a duração média foi de 40 minutos. As entrevistas geradas foram gravadas em áudio e transcritas para posterior análise, e os participantes foram indicados por meio de nomes fictícios.

O uso concomitante de Teoria Fundamentada e Análise do Discurso é uma interface já consolidada em estudos atuais. Segundo Reiner Keller (2005), o exercício de sistematização destas abordagens pode dar conta de uma oscilação muito presente nas análises qualitativas em ciências humanas - que pendem entre macrodiscursos e análises de linguagem em usos excessivamente particulares, compreendidas como extremos. De outro modo, Charlotte Burck (2005) também explora interfaces entre a Teoria Fundamentada, análises discursivas e análises de narrativas compreendendo que permitem uma visão sistêmica e contextual. Dessa análise discursiva, surgiram elementos - fundamentados nos dados - que levaram à aproximação à ideia de comunidades de prática, especialmente, den- 
tro do modelo de Wenger (2001) para a definição de comunidade, articulando eixos como Compromisso Mútuo, Ação Conjunta e Repertório
Compartilhado com as conceituações de prática, onde aspectos como a negociação de significados, processos de aprendizagem, local e estratégias de controle foram elencados.

Tabela 1

Caracterização dos Participantes da Pesquisa

\begin{tabular}{|c|c|c|c|c|c|c|c|c|}
\hline $\begin{array}{l}\text { Informações } \\
\text { Declaradas }\end{array}$ & Ezquiel & Daniel & Joel & Samuel & Jonas & João & Gerente & $\begin{array}{l}\text { Promotor } \\
\text { de Festas }\end{array}$ \\
\hline Raça/Cor & Negro & Branco & Pardo & Branco & Branco & Branco & Branco & Branco \\
\hline $\begin{array}{l}\text { Orientação } \\
\text { sexual }\end{array}$ & $\begin{array}{l}\text { Heteros- } \\
\text { sexual }\end{array}$ & $\begin{array}{l}\text { Heteros- } \\
\text { sexual }\end{array}$ & $\begin{array}{l}\text { Heteros- } \\
\text { sexual }\end{array}$ & $\begin{array}{l}\text { Heteros- } \\
\text { sexual }\end{array}$ & $\begin{array}{l}\text { Heteros- } \\
\text { sexual }\end{array}$ & $\begin{array}{c}\text { Homos- } \\
\text { sexual }\end{array}$ & $\begin{array}{c}\text { Não } \\
\text { declarado }\end{array}$ & $\begin{array}{c}\text { Não } \\
\text { declarado }\end{array}$ \\
\hline $\begin{array}{l}\text { Escolari- } \\
\text { dade }\end{array}$ & $\begin{array}{l}\text { Ensino } \\
\text { Médio } \\
\text { completo }\end{array}$ & $\begin{array}{l}\text { Ensino } \\
\text { Fundamental } \\
\text { incompleto }\end{array}$ & $\begin{array}{c}\text { Ensino } \\
\text { Fundamental } \\
\text { incompleto }\end{array}$ & $\begin{array}{c}\text { Superior } \\
\text { incompleto }\end{array}$ & $\begin{array}{l}\text { Fundamental } \\
\text { completo }\end{array}$ & $\begin{array}{l}\text { Superior } \\
\text { completo }\end{array}$ & $\begin{array}{c}\text { Não } \\
\text { declarado }\end{array}$ & $\begin{array}{l}\text { Superior } \\
\text { completo }\end{array}$ \\
\hline Idade & 50 anos & 23 anos & 18 anos & 25 anos & 30 anos & 26 anos & $\begin{array}{c}\text { Não } \\
\text { declarado }\end{array}$ & $\begin{array}{c}\text { Não } \\
\text { declarado }\end{array}$ \\
\hline $\begin{array}{l}\text { Termo mais } \\
\text { recorrente } \\
\text { para a } \\
\text { atividade }\end{array}$ & $\begin{array}{l}\text { "Profissional } \\
\text { do sexo" }\end{array}$ & $\begin{array}{l}\text { "Garoto de } \\
\text { Programa" }\end{array}$ & $\begin{array}{l}\text { "Garoto de } \\
\text { Programa" }\end{array}$ & $\begin{array}{l}\text { "Garoto de } \\
\text { Programa" }\end{array}$ & "Boy" & $\begin{array}{l}\text { "Garoto de } \\
\text { Programa" }\end{array}$ & $\begin{array}{l}\text { Gerente } \\
\text { da "casa" }\end{array}$ & $\begin{array}{l}\text { Promotor } \\
\text { de Festas }\end{array}$ \\
\hline $\begin{array}{l}\text { Tipo de } \\
\text { clientela }\end{array}$ & $\begin{array}{c}\text { Clientes } \\
\text { recorrentes }\end{array}$ & $\begin{array}{c}\text { Clientes } \\
\text { eventuais }\end{array}$ & $\begin{array}{l}\text { Clientes } \\
\text { eventuais }\end{array}$ & $\begin{array}{l}\text { Clientes } \\
\text { fixos }\end{array}$ & $\begin{array}{l}\text { Clientes } \\
\text { fixos }\end{array}$ & $\begin{array}{c}\text { Clientes } \\
\text { recorrentes }\end{array}$ & $\begin{array}{l}\text { Não se } \\
\text { aplica }\end{array}$ & $\begin{array}{c}\text { Não } \\
\text { se aplica }\end{array}$ \\
\hline $\begin{array}{l}\text { Tempo no } \\
\text { contexto } \\
\text { do sexo } \\
\text { tarifado }\end{array}$ & $\begin{array}{l}\text { Aprox. } \\
20 \text { anos }\end{array}$ & $\begin{array}{l}\text { Aprox. } \\
10 \text { anos }\end{array}$ & $\begin{array}{l}\text { Aprox. } \\
3 \text { meses }\end{array}$ & $\begin{array}{l}\text { Aprox. } \\
5 \text { meses }\end{array}$ & $\begin{array}{l}\text { Aprox. } \\
5 \text { meses }\end{array}$ & $\begin{array}{l}\text { Aprox. } \\
6 \text { meses }\end{array}$ & $\begin{array}{l}\text { Aprox. } \\
30 \text { anos }\end{array}$ & $\begin{array}{l}\text { Aprox. } \\
10 \text { anos }\end{array}$ \\
\hline $\begin{array}{l}\text { Atividade } \\
\text { além do } \\
\text { sexo } \\
\text { tarifado }\end{array}$ & $\begin{array}{l}\text { Cargo } \\
\text { público }\end{array}$ & Não & Não & $\begin{array}{l}\text { Comércio } \\
\text { familiar }\end{array}$ & Não & $\begin{array}{l}\text { Estudante } \\
\text { de Pós- } \\
\text { graduação }\end{array}$ & $\begin{array}{l}\text { Não se } \\
\text { aplica }\end{array}$ & $\begin{array}{c}\text { Não } \\
\text { se aplica }\end{array}$ \\
\hline $\begin{array}{l}\text { Local de } \\
\text { atividade }\end{array}$ & $\begin{array}{c}\text { Rede de } \\
\text { conhecidos } \\
\text { iniciados na } \\
\text { década de } \\
1980 \text { (Rua) }\end{array}$ & $\begin{array}{c}\text { Inicia na } \\
\text { Rua - migra } \\
\text { para Bar }\end{array}$ & Bar & Bar & Sauna & Aplicativos & Bar & Sauna \\
\hline
\end{tabular}

\section{Resultados e Discussão}

Os resultados da análise elaborada, com ênfase nos processos de estabelecimento de comunidades no contexto do sexo tarifado de homens, possibilitaram a compreensão deste fenômeno por meio dos grupos: Homens que se dedicam ao Sexo Tarifado (HST) ${ }^{4}$; HST e Gerências; HST e

4 Considerando que todos os homens que figuram neste trabalho utilizavam ou se reconheciam sob os termos "garoto de programa/profissional
Clientes. Ainda que os participantes desta pesquisa se circunscrevessem em espaços diferentes (Sauna/Bar) e, portanto, com determinadas particularidades, possibilitaram uma análise integrada. Neste sentido, a presente análise se propõe a dar ênfase para os espaços Sauna e Bar em seus aspectos transversais, utilizando-se, eventualmente, dos diálogos com participantes que fa-

do sexo/boy", utilizamos a sigla HST para nos referirmos aos Homens que se dedicam ao Sexo Tarifado especificamente nos locais Bar e Sauna. 
ziam sexo tarifado a domicílio e por aplicativos de celular como forma de diferenciação.

Foi estabelecida a categoria HST como representativa dos espaços Sauna/Bar pelas ligações comunitárias que serão analisadas a seguir, o que parece relacionado ao circuito de sexo tarifado dos HSTs (que para muitos envolve um itinerário nos dois ambientes). Estas dimensões de relação figuraram em campo e nas entrevistas realizadas, de modo que são interpretadas conforme as articulações Compromisso Mútuo, Ação Conjunta e Repertório Compartilhado indicadas neste estudo como eixos centrais na concepção de Comunidades de Prática (Wenger, 2001). Estas compreensões não são vistas como desvinculadas do pesquisador como audiência/ espectador específico e situado nas entrevistas, entretanto, procuram compreender essa relação estabelecida (tanto nas entrevistas como diários de campo) como possibilidades de uma análise contextual e parcial do fenômeno-alvo. Procura-se, neste sentido, desenvolver uma teoria fundamentada nos dados de campo, que responde à particularidade do circuito desenvolvido pelo pesquisador (Charmaz, 2009) através de informantes e da escolha teórica elencada como apropriada.

O primeiro ponto de análise, a esfera relacional dos HSTs, remete a uma dimensão de relação principalmente vinculada a uma "ética do fazer". A manutenção de preços comuns, por exemplo, que acontece principalmente no contexto da Sauna, configura, conjuntamente às noções de sigilo e anonimato (em relação tanto aos outros homens que se dedicam ao sexo tarifado quanto aos clientes de maneira geral), como principais fatores relacionados à noção de compromisso mútuo. Como indica Jonas:

É mais é um acordo entre os boys lá. Eles estipulam um preço pra nenhum cobrar menos, né, porque aí acontece que eles vão ao que cobra menos, então deixa estipulado um preço mais ou menos assim, de 100 a 80 reais, e esse é o preço. Entre 100 e 80 reais. Que ai já fica padrão pra todo mundo, né. E

Todos os nomes utilizados na caracterização dos participantes da pesquisa são fictícios. ai não tem essa de cobrar menos pra me dar bem. Porque, dai, se eles ficam sabendo já dá uma confusão... Porque dai já fica uma desonestidade ali, né. (Jonas)

As formas de sigilo e anonimato mostram-se presentes tanto pelo reiterado uso de nomes fictícios (variando conforme o território), no estabelecimento de relações de proximidade comunicacional com clientes restringida os locais como Bares e Saunas e na recusa sobre qualquer possibilidade de identificar ou caracterizar aspectos da vida dos outros homens que também se dedicam ao sexo tarifado. A configuração de cartel, de negociação consensuada pelo grupo, reforça a ideia de compromisso mútuo. Além disso, essa noção de compromisso mútuo aparece intrinsecamente relacionada a uma conduta masculina, de "negociação entre cavalheiros". Essa dimensão é reiterada em ocasiões em que ocorrem brigas/retaliações em função de troca de tarifas sem a anuência do grupo, remetendo ao uso da força. Em um dos locais observados, uma Sauna, o papel de retaliação em caso de quebra desse compromisso era liderado principalmente por um dos HSTs. Era uma pessoa de presença frequente no ambiente e bastante expansiva, além de se utilizar de atributos como camisetas de times de futebol no final do horário de funcionamento da Sauna, e usualmente iniciava brincadeiras que remetiam a jogos de força e luta, ou a falas provocativas com outros HSTs.

Estes comportamentos remetem a formas tradicionais de exercício de masculinidade. Badinter (1993), em seu trabalho sócio-historiográfico, demonstra como a vida dos homens foi sendo circunscrita por arranjos patriarcais muito vinculados aos ritos sociais e exercícios demonstrativos de força e agressividade. Remetendo-se a ritos de passagem característicos de várias culturas, nas quais o "tornar-se homem" é um processo de identificação com um novo estatuto dentro da comunidade, a autora evidencia que as questões relativas a este "ser homem" se dão numa dimensão cotidiana, pela via da prova pública. O campo das masculinidades no qual Badinter se debruça é compreendido aqui como associado às considerações de Connell e Messerschmidt (2013) e Kimmel (1997), que indi- 
cam a existência de determinadas expectativas em relação aos homens - como certas provas de força, honra e valentia - aspectos reiterados cotidianamente por homens e mulheres em locais como escolas, clubes e no contexto familiar, por exemplo.

O local da Sauna em que estas interações aconteciam com mais frequência, como brincadeiras e provocações, era principalmente a área de shows, e, em determinados dias, em uma de suas paredes, se reproduziam jogos de futebol. Essas formas de construção do espaço e de manutenção de relações, que também compreendem aspectos arquitetônicos, chama a atenção se atentamos para o que Welzer-Lang compreende como a "casa dos homens" (2001, p. 462). O termo cunhado pelo autor procura definir o conjunto de lugares e espaços destinados à estruturação do universo masculino - como grupos de interação na escola, clubes, cafés ou outras comunidades - palcos de combates árduos no que se refere a comportamentos, ou características, que poderiam se assemelhar às tradicionalmente relacionadas às mulheres. Estes espaços, nos quais o homoerotismo pode ser experimentado em diferentes graus e dimensões, permitem a incorporação de saberes organizados em códigos e nos quais a aprendizagem se conduz pela via do sofrimento, como também atenta Badinter (1993). O contexto de homossocialização que se interpõe na Sauna, convive com estas e outras manifestações de virilidade associadas à heteronormatividade - e que frequentemente flertam com fatores como o exercício da violência, intrinsecamente relacionados à manutenção do grupo.

Outros aspectos figuram como representativos e intrinsecamente relacionados, como a noção de ação conjunta. Existe uma percepção, no que se refere à Sauna, que "são os boys que fazem funcionar" (Jonas). A afirmação de Jonas mostra como o processo comunicacional permite pensar em processos de resistência, atividades e formas de agenciamento frente a possíveis explorações, remetendo ao que Paechter denomina "prática enquanto local" (2003, p. 73). Essa noção, entretanto, figura de forma mais amena no contexto do Bar, no qual a Gerência é mais ativa e opinativa em relação aos HSTs. Esse distanciamento/aproximação da Gerência parece dar vazão para formas diferentes de organização conforme o contexto. Ainda figurando no que compreendemos como ação conjunta por parte dos HSTs, a questão da abordagem (vinculada a uma conduta respeitosa e de tom cavalheiresco) figura nos dois espaços. Entretanto, a organização da abordagem no contexto do Bar, no qual a vigilância da Gerência é mais presente, é mais rígida e evidente.

Para além dos aspectos relacionados à composição desta comunidade de prática em termos de compromisso mútuo e ação conjunta, vemos que estas esferas não se dão desvinculadas de um repertório compartilhado no contexto do sexo tarifado. Aspectos como o exercício de códigos vinculados a masculinidades tradicionais (por exemplo, a utilização de certa estética de "mano" ou "malhado") e o discurso do "dote" como representativo de virilidade. Dentro deste espectro, é evidente o uso restritivo de drogas como estratégia para o controle das performances de masculinidade e virilidade - como trejeitos, olhares, andares e disposição sexual. A ideia de que o cliente procura por afeto e que é guiado pela falta parece indicar um processo discursivo que nomeamos "dessexualização do cliente", um jogo de poder no qual há certo desinvestimento protetivo que afasta o HST da possibilidade de identificação com uma ideia de conjugalidade em contexto homossexual.

Outras formas de vivenciar o sexo tarifado mostram como a noção de territorialidades se interpõe, implicando modos de vida, formas de linguagem e trocas simbólicas (Perlongher, 2008; Toneli \& Perucchi, 2006). Dois dos participantes entrevistados se caracterizavam de forma discrepante em relação aos HSTs que figuravam nos espaços Sauna/Bar. Ezequiel (homem negro, por volta dos 50 anos, heterossexual, funcionário público, classe média baixa e renda estável), que não frequentava os locais de Sauna e Bar, se identificava como profissional do sexo e realizava encontros com clientes a domicílio, indicou uma dimensão diferente das dos outros homens no que concerne ao sexo tarifado em sua vida. A fala de Ezequiel, que descreve seu fa- 
zer como uma atividade mais próxima de uma perspectiva técnica do sexo tarifado demonstra uma esfera na qual ser bom profissional envolve uma dimensão ética bem delimitada e com pouca margem a prazeres ou deslizes afetivos:

O bom profissional procura manter o cliente, cativar o cliente, até porque é como eu te disse, muito clientes me indicavam pra outros clientes. E o mal profissional não, a pessoa nem vai querer ver mais aquela criatura. Ai é aquela coisa, muitas vezes, como eu te disse, não só às vezes, o profissional do sexo pode atuar como uma espécie de psicólogo, claro, sem formação, mas aquela coisa de ouvir e dar atenção, porque tem muita gente carente nesse meio. E ai que surge os picaretas e aproveitadores que se aproveitam disso pra extorquir a pessoa, pra drogar e pra roubar. Porque essas pessoas querem ajuda, porque estão com problemas, eles pagam, mas dizem: "Ah, eu não quero fazer programa, eu só quero desabafar, eu quero a companhia, pra ficar um tempo em casa ou ir em um bar ou em um cinema, né". E eu sou uma pessoa sem mistério,que sou paciente pra ouvir os outros, até já me disseram: "Tu seria um bom psicólogo, um bom psicanalista", porque tu tem paciência para ouvir as pessoas." $E$ isso ai me ajudou muito a conseguir bastante clientes. (Ezequiel)

A construção argumentativa, acerca das possibilidades de legitimação da prostituição como fazer de demandas éticas, utiliza da audiência - o pesquisador - como possibilidade de aproximação e afirmação. O tom é professoral e marca como o entrevistador encontra-se em uma fase muito periférica de apropriação dos significados das práticas nessa comunidade. Ser um profissional de boa escuta figura como central na atuação de Ezequiel, de modo que, ao mesmo tempo em que implica uma série de demandas de cuidado para o seu fazer, compreende o sexo tarifado como ação na qual a dimensão do sexo e a do prazer são dignas de atenção, mas no sentido de controle. Mesmo que os participantes que frequentavam Sauna/Bar desta pesquisa reiterassem a perspectiva de que a aparência do cliente importa, para Ezequiel a esfera do trabalho supõe uma negociação em que o preço justo não é medido pela aparência física ou por dimensões afetivas, mas sim por uma visão mais operacional e restritiva:

É aquela coisa, tudo é combinado antes, né. Eu digo: $O$, isso eu faço. Tipo: eu não faço sexo oral em homens, em mulheres eu até faço, aí eu digo pra eles que não faço sexo passivo, só ativo, e eles aceitam, no caso, isso... (Ezequiel)

Além da separação entre a dimensão do interesse sexual em nome de uma legitimidade tecnificada do trabalho, Ezequiel identificava separações entre os homens que frequentavam o itinerário do sexo tarifado em Porto Alegre. Por meio das atribuições "bons profissionais" e "aproveitadores" (ou picaretas) sugere o investimento numa relação de confiança com a clientela e uma demanda compartilhada entre os atributos de um profissional da área. $\mathrm{O}$ posicionamento de Ezequiel em relação ao sexo tarifado, que leva em conta uma dinâmica entre clientes, colegas e "picaretas", não se faz desvinculado de uma noção específica de trabalho legítimo. A resposta "técnica" de sexo tarifado por parte de Ezequiel pode falar de uma noção de desejabilidade moral de atividade profissional em questão que faz com que a proximidade afetiva se manifeste controlada pela via de uma noção de escuta profissional, assim como aspectos geracionais podem sugerir uma performatividade mais restritiva no que concerne a exercícios de sexualidade.

Para o participante João, que assim como Ezequiel também não atuava no contexto Sauna/Bar, mas que utilizava aplicativos de celular com fins de realizar sexo tarifado, esta dimensão de reconhecimento também difere. João era um jovem universitário, realizando seus estudos de mestrado, branco, único participante a se declarar homossexual e de família economicamente abastada. Para este participante o sexo tarifado estava mais relacionado a uma experiência de prazer em ser desejado, em ter relações sexuais prazerosas e experiência de vida:

- No meu caso era isso, eu só queria saber como era. . . . Evidentemente eu não sou alto, forte e dotado... porque em geral 
a propaganda do GP (Garoto de Programa) é... dotado. É quantos centímetros. E pra mim realmente é uma coisa tipo: $\mathrm{Meu}$, ah, qual é?, né, é besteira... Então, eu sempre na conversa deixava claro. Tipo, se você está procurando alguém para foder loucamente, tipo... não sou eu. Eu sou mais do tipo... carinho, conversa... Transar, claro, mas não aquela coisa mecânica. E obviamente tem quem acabou querendo me encontrar, estava interessado nisso. Não na coisa do vamos "foder" loucamente. Uma coisa que eu acho interessante, engraçada, é que não tem GP passivo, né, é só ativo, né. Eu acho que eles se dariam melhor se fossem passivos.

- Tu achas? Por quê?

- Não sei, acho que porque geralmente, pra você dar, é menos uma coisa... sei lá, física, ou uma coisa de sexo só, agora comer é muito mais tipo: ah, é um cu, tá bom. Pra dar, pelo menos eu pra dar e sentir prazer, não é tipo: aí, quantos centímetros têm? "Mas se eu gosto da pessoa, né..."

Neste fragmento da narrativa, João articula questões que o distanciam do contexto de comunidade estabelecido pelos outros HSTs. Além da dimensão de prazer guiar seu itinerário no sexo tarifado, João faz uma separação qualitativa entre a sua forma de se posicionar no sexo tarifado e dos outros homens que se dedicam a este fazer. A reflexão sobre sua aparência, diferente do imaginário do garoto de programa como sujeito de performances hipermasculinizadas, se articula com a compreensão de que o tipo de relação sexual que oferece não é "mecânica" ou "louca" (sem afeto e intenso), mas sim de um momento de carinho e suavidade, de "sexo fofo", como se referiu em outro fragmento da narrativa (sic.). Além disso, mostra-se presente um processo de ambiguidade entre ser ou não ser GP quando se reitera no discurso de que ser "passivo" no ato sexual não tem as mesmas implicações do ser "ativo". João parece se afastar da prática do sexo tarifado como dimensão técnica, ressaltando o prazer, e desprazer, envolvidos.

A compreensão de que a imagem esperada do HST é hipermasculinizada, e o sexo dos outros HSTs como destituído de afeto, funciona na narrativa como uma maneira de se distanciar desta comunidade de prática. Este processo de diferenciação não se manifesta somente nestas esferas, mas também se apresenta na própria utilização de termos indicativos da atividade. Quando questionado sobre como nomeava esse fazer, respondeu:

Tipo: "Ah, tu faz o que, e tal...", não usando nenhum termo especifico... ou: " $A$ h, você é GP”. GP é o mais comum. Só fala GP, ai um ou outro tipo: "Ah, mas GP...". GP o quê? Dai eu: "Não, garoto de programa". Porque nem todo mundo conhecia a sigla, né. Mas o nome nunca... não me chamou a atenção...Os outros usam GP, eu também... (João)

A utilização do termo GP parece uma resposta às abordagens de clientes, ou a certo uso mais comum no contexto porto-alegrense e meios de comunicação para se referir aos homens que se dedicam ao sexo tarifado. Entretanto, mesmo pelo termo "GP" figurar também no espaço do Bar, a forma de utilização denota um uso mais apropriado - entre os HSTs da Sauna e Bar a diferenciação remete ao território, para João, não. O uso dos termos "GP/boys" nos contextos respectivos de Bar/Sauna é contextual e remete a funcionamentos dos locais de exercício das atividades de sexo tarifado, mas resguardam similitudes quanto à comunidade de prática ${ }^{6}$.

Por fim, no que concerne ao contexto da comunidade de prática HSHs, ou seja, dos espaços Sauna/Bar, cabe salientar que os processos de compromisso, ação e repertório não parecem funcionar sem ambiguidades e resistências. A existência de homens que se deslocam com maior possibilidade destes conjuntos normativos (ética de relação com a "casa", com colegas e com os clientes) geralmente está vinculada a marcadores sociais que posicionam determina-

6 Compreendem um itinerário urbano mais extenso que não é alvo de considerações neste trabalho. No processo metodológico escolhido, o pesquisador deste estudo esteve em cinco locais que formam certa rede de socializações para além do Bar e da Sauna - aqui elencados como locais prototípicos. 
dos sujeitos em situações de privilégio. Marcadores sociais de diferença como cor, classe e escolaridade posicionam estes sujeitos com mais ou menos condições de agenciamento neste contexto comunitário. A partir dos diários de campo e dos itinerários narrados nas entrevistas, percebemos que, de forma geral, os rapazes mais assíduos nos locais eram os mais suscetíveis a represálias no caso de quebras de conduta. De outra forma, os rapazes que mais tinham clientes fixos (e que, portanto, podiam frequentar menos o local) eram, em geral, brancos e/ou de maior escolaridade e/ou com potencial econômico mais estável - tendo maior mobilidade, ganho financeiro/tarifado e, portanto, maior segurança.

Se estes aspectos são performatizados por homens, num exercício de conexão com o que expõe Butler (2002), cabe atentar à pluralidade de "ser homem" e das formas de exercício de masculinidades envolvidas. Mara Viveros-Vigoya (2011) põe em pauta esta questão compreendendo que é necessário conceber contextos específicos e os diversos marcadores sociais envolvidos, como gênero, "raça" e sexualidade, por exemplo, que permitem questionar-se sobre as diversas possibilidades de ser homem dinamicamente. Em contextos muito diversos, como o escolar, ou seja, envolvendo pessoas na mais tenra idade, estudos atentam para as diferenças nas performances de masculinidade e das atribuições do "ser homem", vinculadas a marcadores de diferença como cor e dinâmicas de gênero (Caetano et al., 2015).

A partir destas considerações compreendemos que a Sauna e o Bar, neste estudo, configuram o núcleo da comunidade, de modo que os outros HSTs (João e Ezequiel) exemplificam posicionamentos mais periféricos em relação ao circuito de sexo tarifado elencado. Estes dois homens compartilhando alguns, mas nem todos os elementos envolvidos nesta prática. Ainda que reconheçam a existência deste itinerário de Bares e Saunas pela cidade, e compreendam aspectos simbólicos envolvidos (como uso de termos) constituem suas experiências guiadas menos pela subsistência (em relação à maioria dos HSTs nos locais fechados). Além disso, os discursos de identificação e prática sexual parecem mais extremos, posições nas quais Ezequiel estaria mais próximo de uma masculinidade tradicional (mais restritivo em relação ao tipo de performance no sexo com os clientes) e João mais próximo de um exercício de sexualidade guiado pelo seu prazer identificado como homossexual (performances no sexo com os clientes que lhe agradam e lhe satisfazem).

Outro sistema compreendido como comunidade de prática ocorre também nas dimensões comunicacionais HST/Gerências. Essa comunidade pode ser caracterizada pelo uso de estratégias conjuntas que também dizem respeito à manutenção das negociações nos locais de sexo tarifado. A compreensão de compromisso mútuo, nesta esfera, se manifesta pela via do bem- estar dos HSTs no Bar e na Sauna. Se no Bar o processo de garantia do bem-estar é por meio de jantares diários e bebidas para "relaxar" antes da chegada dos clientes, na Sauna a ideia de bem-estar está presente pela via das festas disponíveis: “Quem é 'do ramo' quer estar comendo, bebendo, vendo shows e se divertindo gratuitamente. Quem paga todo esse carnaval são os clientes. Os boys aproveitam" (Promotor de festas). A estratégia desenvolvida pela Gerência da casa para clientes e HSTs funciona com Jonas, um dos HSTs da Sauna. As festas na Sauna, em especial nos fins de semana, são indicadas pelo boy como eventos nos quais o lucro é menor, mas a diversão é garantida. Além desta noção da diversão como um processo de manutenção da relação Gerências/HST, ainda figuram como questões o não uso de drogas ilícitas, roubo, tráfico e o sigilo - como conjunto de aspectos que dizem de uma ética relacionada ao fazer sexo tarifado nos locais.

Compreendendo essa comunidade pelo quesito ação conjunta, podemos ver que existem táticas estrategicamente situadas de modo a facilitar a concretização dos encontros. Um dos boys, ou seja, que frequenta especificamente o contexto da Sauna, indica a disposição arquitetônica - especificamente a exibição de filmes heterossexuais - como uma artimanha conjunta: Agora eu tô com um cliente fixo, né, e ele é muito gente boa, bah! . . Mas às vezes tu pega uns que bãhhh, é difícil. De aparência, 
de tudo. Bah!, tu vê de tudo um pouco. Sem falar que às vezes tem umas "múmias" lá, né. E aí, pra ti fazer o serviço ali é complicado... . . É... normalmente tem vídeo hétero no quarto, ai tu vai vendo um pornôe vai. E aí, depois tu vai pegando o jeito. Mas no começo é dificil, cara, pra levantar ali, pra fazer funcionar.... (Jonas)

Apesar de, para a gerência da Sauna, o fazer dos HSTs serem um "carnaval", Jonas indica algumas dificuldades e contratempos relacionados ao trato com os clientes. O sexo tarifado, ainda que com mais ou menos intensidade, trata de negociações nos quais o âmbito do desejo é presente. Esse atravessamento, entretanto, faz atentar para o sexo como exercício de socialização e erotismo que não são "naturais". O desejo, segundo Bensusan (2006) é circunscrito por construções sociais e históricas. Nesse sentido, é intrinsecamente relacionado a processos políticos (Bensusan, 2006; Pelúcio, 2014), nos quais a conexão entre o considerado "erótico" e as histórias das pessoas, assim como possibilidades de reflexão sobre discursos sociais, permitiriam compreender os corpos como plataformas socialmente implicadas (Bensusan, 2006). Outro aspecto relacionado à ação conjunta são os jantares e festas temáticas, nos quais é possível a exibição, e o sorteio de HSTs. Este tipo de evento acontece especialmente no Bar, e conta com aparatos de avaliação e formas de prestigiar a beleza e os atributos físicos dos homens. Além deste aspecto, no Bar figura a indicação de HSTs apropriados para clientes específicos - de acordo com características pessoais identificadas pela Gerência (gostar de dançar, de ir a festas, considerados pelo Gerente os mais "inteligentes" ou com atributos físicos que mais agradam, etc.)

Neste contexto comunicacional, de HST/ Gerências, é possível interpretar como aspectos de repertório compartilhado em especial o discurso de controle/proteção. Exercer as atividades em espaços fechados, para os HSTs, permite vantagens como segurança e circulação contínua de possíveis clientes, entretanto, faz com que estes estejam sujeitos às normas do local que se frequenta. Para a gerência, a possibilidade de ter HSTs circulando aumenta as vendas de bebida, aluguéis de quartos/cabines e entradas nos ambientes. Essa negociação com base na ideia de controle/proteção parece muito vinculada a processos "pedagógicos" (Louro, 2011, 2008), no qual o repertório compartilhado, assim como em outras dimensões, não está estático, mas sim em constante construção. No Bar é possível observar uma atuação próxima e regrada em relação à circulação dos HSTs: os homens devem sair cada um de uma vez para fumar, devem estar limpos e com uma vestimenta apropriada, não devem estar sob o uso abusivo de substâncias, etc.

O contexto de articulação entre Gerência e HSTs ainda reitera, por meio de conversas e práticas, formas de vestuário e de se portar - como no trottoir pelo ambiente - certa lógica de que " $o$ que os clientes buscam é cara de pau grande e que seja homenzinho, porque biba não gosta de mulherzinha" (Gerente, Bar). Este aspecto está intrinsecamente relacionado a relações pedagógicas envolvidas, entretanto, cabe atentar que esse discurso estereotipado sobre o que os clientes buscam não é monológico, mas polifônico, como ressaltava João sobre seus atributos físicos e suas práticas sexuais com clientes que diferem dessa concepção normativa. Ele mesmo, em diferentes momentos das entrevistas, se referiu a si mesmo como "puta", mesmo que de forma irônica, mas assim, no feminino, reforçando a ideia de outras identificações possíveis no exercício da prostituição de homens. Neste aspecto podemos notar como a dimensão territorial também influi na manutenção da comunidade de prática.

O controle, a vigilância e a tutela figuram nos dois ambientes e são manifestados ligados a interpretações essencialistas sobre o "ser homem" no sexo tarifado, entretanto, demonstram que este repertório compartilhado não é um fenômeno estável, mas sim contextual e que influencia em formas de tratamento - entre elas punitivas. $\mathrm{O}$ aspecto tutelar no Bar está relacionado a uma ideia de que parte dos homens que frequenta foi "retirada" das drogas e da rua e precisa ser direcionada pelo gerente. Na Sauna, essa forma de controle e cuidado, operacionalmente, é mais vinculada ao grupo interno de HSTs. Entretanto, na Sauna a noção de vigilância se manifesta, como mostra um Promotor de Festas, 
nutrida pelo discurso de que o sexo tarifado está intrinsecamente vinculado à ideia de vício, ganância e mau-caratismo, e que, portanto, exige cuidado redobrado dos clientes e gerência para com os HSTs que frequentam o local.

. . como os boys, como nós chamamos, são rapazes inteligentes, que estão lá para ganhar dinheiro, eles têm a mesma capacidade de um vendedor de automóveis, de um vendedor de imóveis, e de um vendedor da bolsa de valores. Mas eu não acredito em fidelidade. Não acredito em fidelidade de garotos de programa, a prostituição é um vício, é a forma de ver, de entender $e$ de comunicar, a prostituição é como o vício da cocaína, do crack, do cigarro, da bebida. Porque... quando o camarada, o jovem, entra pela primeira vez na sauna para se prostituir, e um cliente diz "Ai, eu vou pegar esse, esse é ingênuo, não é prostituto ainda, vou me casar com esse cara". Esse dono de sauna me disse que quando esse cara entra lá dentro a alma dele já é de puta. Então, mesmo que alguém o encontre e o tire dessa vida pela primeira vez, ele continua mentalmente, espiritualmente, e corporalmente, sendo um homossexual. Mas não somente um homossexual, um homossexual em que o dinheiro está em primeiro lugar. Portanto, ele não vai deixar de ser garoto de programa enquanto seu corpo e a sua beleza permitir ... (Promotor de festas)

Figuram nesta fala alguns aspectos que demonstram a pluralidade de discursos que influem na relação entre gerência e HSTs. A capacidade de negociação dos HSTs, dita como muito potente, é ligada ao uso desse potencial de forma enganosa para com o cliente. Figura, além disso, um discurso de fidelidade que mostra a ambiguidade do fazer dos HSTs em relação aos clientes (mesmo no discurso da gerência). A fidelidade, no momento que é posta em contraposição à ideia de prostituição (tomada como fazer ligado à ideia de vício), mostra-se como aspecto desejável e indica a ambiguidade relacionada ao fazer no sexo tarifado. Mesmo em um contexto de Sauna, e na posição de gerência como fiador dos discursos sobre sexo tarifado, uma percepção moralista sobre o fazer dos HSTs está presente. Ser HST, nesta percepção, demonstra o aspecto do exercício de sexualidade como vinculado à manifestação de certa verdade íntima, anímica, profunda e fundamental, como foi discutida por Michel Foucault (1988). O gerente de sauna indica o fazer dos HSTs no âmbito da patologia, no qual o mau-caratismo e a infidelidade estão como manifestações desta "alma de puta". Neste contexto, o homem cuja alma "já é de puta" é entendido como um homossexual instrumentalizado pela capacidade de venda e guiado pela ganância, ou seja, está determinado a ser desta forma. Estes esforços classificatórios parecem próximos da constituição de uma anormalidade como forma de reiterar uma ideia de normalidade, mesmo no contexto dissidente do comércio sexual. Tal lógica é corroborada pelo depoimento do Promotor de Festas, quando afirma: "Eles são especialistas. Na cama eles te fazem acreditar que você é Dalila e ele Sansão. Ou que o cliente é a Madonna e ele o Jesus Luz".

A diferença elencada pelo participante no que concerne a esta dimensão gay/HST está também voltada para uma série de comportamentos nos quais a aproximação com uma conduta feminina, na relação com o cliente e na realização do encontro sexual, parece determinante:

. . . há uma diferença entre garoto de programa, que eu também considero gay, e gay que é garoto de programa. É uma diferença pelo comportamento, porque o gay tem um comportamento um pouquinho mais afetado. O gay já lança olhares, que o boy não. O boy fala um papo de macho que vai pra cama com outro macho e que não importa o que vai acontecer, é só uma questão de valores. (Promotor de festas)

Para o promotor de festas, o fazer dos HSTs no local está circunscrito por uma forma de ser bastante restrita. Os HSTs são "machos" que obedecem a uma conduta de distanciamento do prazer que lhes garante uma determinada composição comportamental essencialmente diferente da "gay", guiada por valores. Ou seja, a realização do sexo neste contexto, e para os "machos" em específico, se justifica pela via do consumo e da negociação dos valores envolvidos. 
De outra forma, o uso de termos que remetem ao feminino - que está particularmente ligado ao contexto pejorativo do sexo tarifado - figura não só nesta narrativa, aspecto que será retomado na próxima descrição de comunidade de prática HST/Clientes.

Na comunidade de prática HST/Gerência a possibilidade de punição é presente e parte constituinte da relação, estando muito relacionada à dimensão territorial. A punição pode ser pela via da "suspensão", como acontece no contexto do Bar. Considerando que o uso de aplicativos e Internet, para os HSTs deste local, é evitado e indicado como proteção (estar presencialmente é visto como forma de garantir anonimato), a realização de encontros com clientes parece se dar vinculada ao cotidiano do Bar. Com isso, a escolha da punição pela via da suspensão, como é feita pelo Gerente do Bar, parece efetiva, já que pode impedir o encontro com a clientela. Entretanto, isso figura de forma muito mais efetiva no caso dos homens que têm certos marcadores de diferença (Brah, 2006), como ser economicamente menos favorecido. Joel, por exemplo, repreendido em determinado período por traficar no ambiente do Bar, indicou dificuldades de estabelecer contato com os clientes e concomitantemente uma diminuição no ganho mensal. Ainda que a vivência no tráfico tenha sido uma forma de aumentar a renda para Joel, por exemplo, esse problema não era uma questão para Jonas, que não pecisava recorrer a outras formas de ganho em função da permanência dos clientes fixos e da renda de sua família. Nesse sentido, este sistema de quem pode ser punido também é atravessado por outros vetores, o que reitera a ideia de que ser "michê" supõe uma pluralidade (Perlongher, 2008) e não uma homogeneidade em seu fazer.

A última dimensão de comunidade de prática analisada neste estudo é composta pela articulação HST/Clientes. No que se refere à noção de compromisso mútuo, compreende-se que existe um tratamento, ou etiqueta, vinculado ao processo de sedução e abordagem. Esse tipo de etiqueta, que é caracterizada, por exemplo, por certa ordem na abordagem - cada HST tem seu tempo de conversa e negociação garantido, sem a interrupção de outro HST - e se estende compreendendo a confidencialidade e o anonimato como pressupostos. Além dessa dimensão, as questões vinculadas à noção de ação conjunta fazem atentar para certa manutenção da ideia de que o cliente tem mais controle ou poder na negociação. Esta ideia de que o cliente tem mais poder, manifestada na abordagem e no processo comunicacional, é reiterada pelo HST em sua interação com o cliente, mas não na relação com outros HSTs, onde o ideal na virilidade precisa ser reforçado através da alusão à representação da concessão teatral de poder ao cliente, já que esse reside no macho (ou naquele que o representa). Essa relação de poder mostra-se mais complexa ainda quando se analisam as diversas dimensões envolvidas - o HST escolhe os clientes que acha adequado; dimensiona seus ganhos e possíveis problemas; muitas vezes tem por subsídio um conhecimento prévio derivado de conversas internas entre os HSTs. Este aspecto é particularmente evidente em HSTs com mais tempo na casa, como indica Jonas:

. . eles já conhecem todo mundo que vai, que são do meio, aí eles vão em um, vão em outro ... já conhecem aquele mundo, já sabem quem que paga, quem que tem dinheiro, que não vai te enrolar... Eu já sei uns lá que só tão ali querendo enrolar... e tem uns que o pessoal já diz: Não, esse cara paga bem, ah, esse aí já não paga tanto, com aquele lá só vai em último caso.... (Jonas)

Essa relação não se dá sem conflito, visto que quanto mais o HST tem poder sobre a relação e possibilidade de escolha, mais parece ser presente um discurso de essencialização no que concerne à ganância e mau-caratismo. De outro modo, a ação conjunta, que pode ser tomada pelo processo de negociação e realização do sexo tarifado, pode gerar uma dimensão não prevista de relação que, ainda que não seja contraditória, aparece cheia de ambiguidades. É o caso dos clientes fixos, que parecem demandar uma dedicação afetiva e de tempo não previstas por alguns dos HSTs:

Pelo que eu vejo, acho que falta alguma coisa na vida deles e eles procuram uma coisa mais afetiva assim, sei lá... acho que eles 
anseiam por um relacionamento. Acho que eles não vão lá procurar só por sexo. Eles vão lá encontrar alguém, porque é ali onde que eles vão. Ai eles querem transformar aquilo em um relacionamento. Que nem esse meu fixo, eu nunca ia imaginar que ele ia querer sair comigo, agora me liga todo dia. (Jonas)

Dentro deste panorama, parte da ação compartilhada é especialmente notável quando confrontada. Alguns clientes podem ser vistos nessa posição que foge à norma da "casa". É o caso de um dos clientes no Bar, reconhecido por pagar quantias grandes em dinheiro e um cliente desejado por muitos dos HSTs. A negociação com este cliente parecia dificultada, principalmente porque este falava abertamente de práticas nas quais os HSTs desempenhavam atividades relacionadas à posição reconhecida como do âmbito da "passividade". Uma das demandas deste cliente, como indicaram o gerente e um funcionário do Bar, era depilar as nádegas dos HSTs antes de "darem o cú" (Gerente, Bar). Parece haver certa dimensão de rito neste fazer, que se estende para o campo das relações no Bar. Esse cliente, que alardeava suas atividades sexuais com os homens do Barintitulando os HSTs com quem tinha encontros de "meus fêmeos" - mostrava que a quebra nessa negociação do âmbito da ação compartilhada contrapõe-se à manutenção da virilidade e masculinidade tradicionalmente associada ao HST. Essa forma de atuação, entretanto, não é unilateral, sendo que em discussões no Bar é possível, mesmo que raro, ver HSTs chamando clientes de termos como "putões" ou "bichas" em tom pejorativo e agressivo.

$\mathrm{O}$ uso de termos que remetem ao feminino, não figura somente como forma estratégica para a agressão, ou somente nos espaços como Sauna/Bar. Para João, participante que realizava encontros com clientes por meio de aplicativos de celular, também usava o nome "puta" para se descrever situações específicas no sexo tarifado, no qual a posição servil entra em jogo. Em uma madrugada, chegando em um prédio em uma região nobre da cidade, João foi direcionado pelo porteiro a entrar pelo elevador de serviço:
- Achei interessante que tu colocas assim, para o cara que te atendeu... "Ah, será que ele sabe que eu sou puta?".

- É, porque... Aquele dia, ele me mandou pro elevador de serviço, daí eu tipo..., não que eu fiquei indignado, mas tipo: elevador de serviço? Entendeu?... Ai eu fiquei tipo... hum, tô aqui fazendo um serviço.. Quem são as outras pessoas que ele manda usar esse elevador? (João).

Estes termos que remetem ao feminino, ligados ou representativos de características ou situações pejorativas, indicam a lógica de vigilância que permeia os ambientes estudados, assim como os possíveis conflitos envolvidos com as formas legítimas de ser homem nestes ambientes, e fora deles. Essa ansiedade gerada pela proximidade com o feminino está presente em diversos trabalhos (Kimmel, 1997; Torrão, 2005; Welzer-Lang, 2001) e aqui mostra-se contextualmente presente. Para Perlongher (2008), por exemplo, a dimensão de perigo do efeminamento do michê é digno de atenção e aqui também mostra-se presente. Esta composição faz atentar para estas hierarquias do masculino/feminino como vivências que se relacionam com o sexo tarifado, relacionadas com o corpo feminizado como espaço de violação e subalternidade (Gregori, 2003). Outros estudos também indicam que as masculinidades são intrinsecamente relacionadas a comportamentos como o uso da força e formas específicas de experienciar relações sexuais, por exemplo (Connell \& Messerschmidt 2013; Kimmel, 1997). Neste contexto, os atravessamentos institucionais relacionados a estas expectativas de gênero e sexualidade levam os sujeitos a intuir certo modo de ser masculino que pode se manifestar por meio do afastamento com dimensões da vida consideradas do campo feminino (Caetano et al., 2015).

Esse aspecto dá ensejo para pensarmos em outra dimensão da vivência entre HST/Clientes, o repertório compartilhado. A noção de repertório compartilhado pode ser interpretada tendo por questões, por exemplo, a estética envolvida em ser HST/Cliente. Certa imagem que se faz do possível cliente e possível HST, como mostra a incursão do pesquisador em campo, faz atentar 
para um repertório desta estética identificatória. Como ser jovem pode remeter à posição de HST, vestimentas que denotem uma vida endinheirada - que se afastam de estéticas como as de "mano", malhado ou de "malandro". A posição do pesquisador, neste quesito detentor de certa ambiguidade, demonstra essas percepções: ser reconhecido como possível HST por homens mais velhos ou possível cliente por HSTs (como me disse um HST: "Por que você está vestido como cliente?") elucida questões dessa dinâmica. De outra forma, é notável como a dimensão estética no processo de "caça" não é unilateral e envolve tanto HSTs como clientes. Se os HSTs se posicionam nestas estéticas de malandro, malhado ou "mano", o vestuário caro dos clientes e as mesas cheias de Red Bull não parecem fortuitos. Como diz o promotor de festas e gerente de uma Sauna em relação à sua interpretação sobre a lógica de funcionamento destes locais:

Todo mundo que vai num açougue quer carne nova, né, eu vejo dessa forma. Eu não vejo as pessoas como carne, eu vejo as pessoas com carinho e com amor, até porque eu sou católico e sempre procuro ajudar meus semelhantes. Mas a vida é essa, né, todo mundo quer comprar e quem tem dinheiro sempre compra o que é melhor (Promotor de festas).

\section{Reflexões Finais}

Este artigo procurou analisar a configuração de comunidades de prática de sexo tarifado de homens em Porto Alegre, considerando as articulações discursivas relacionadas a exercícios de sexualidade e identificações de gênero. As relações interpretadas como constituintes, que no caso dos HSTs requerem análises quanto à abordagem, às lógicas de sigilo e anonimato envolvidas, às negociações quanto ao cartel de valores e uso de força para firmar estas relações, fazem atentar para atravessamentos que mostram que as práticas envolvidas estão imersas em dimensões discursivas. Da mesma forma, no contexto da comunidade HST e Gerência, a manutenção do bem-estar dos HSTs, a disposição de filmes heterossexuais, a realização de eventos e con- tatos no local de sexo tarifado, assim como as lógicas punitivas envolvidas circunscrevem-se por discursos essencialistas sobre quem é esse homem que se dedica a vender momentos de encontro. Por fim, a dinâmica vinculada aos HSTs e Clientes, que demonstra certa lógica de etiqueta e teatralizações na qual o cliente parece deter uma posição de privilégio sobre a negociação, é evidenciada pelas quebras dessa conduta silenciosa: mescla-se com momentos de conflito em que o discurso de feminização do outro é forma de agressão.

As três dimensões elencadas HSTs, HST/ Gerência e HST/Clientes, oportunizam uma visão que não compreendemos como deslocadas de uma intensão comum: a manutenção dos ambientes de sexo tarifado. Entretanto, cabe atentar que as dinâmicas estabelecidas se dão pela via da vigilância e da correção, de modo que se constituem e reiteram corpos dignos de legitimidade e, portanto, consumíveis dentro desse espectro relacional. Discursos de essencialização vinculados a certa concepção de "alma de puta", à noção de quais prazeres são genuínos e legítimos, e a determinadas formas de ser e de aparentar - pela via do ser "homenzinho", ou "macho" - dão ênfase para as relações de poder nas quais estereótipos clássicos de virilidade e masculinidade estão presentes. Formas de "dessexualização" do cliente, como nos momentos em que HSTs ressaltam que seus clientes querem principalmente uma relação de companheirismo e atenção, se compõem numa dimensão na qual se opera certa dissociação entre orientação sexual e prática como forma de reiterar a heterossexualidade e virilidade.

\section{Referências}

Badinter, E. (1993). XY: Sobre a Identidade Masculina. Rio de Janeiro, RJ: Nova Fronteira.

Ballester, R., Salmerón, P., Gil, M. D., \& Giménez, C. (2014). Sexual behaviors in male sex workers in Spain: Modulating factors. Journal of Health Psychology, 19(2), 207-217.

Baral, S. D., Friedman, M. R., Geibel, S., Rebe, K., Bozhinov, B., Diouf, D., Sabin, K., ...Chan R. (2015). Male sex workers: Practices, contexts, 
and vulnerabilities for HIV acquisition and transmission. The Lancet, 385(9964), 17-23, 260-273

Bar-Johnson, M. D., \& Weiss, P. (2015). A comparison of male sex workers in Prague: Internet escorts versus men who work in specialized bars and clubs. The Journal of Sex Research, 52(3), 338-346.

Barreto, V. (2012). "Vamos fazer uma sacanagem gostosa?" Uma etnografia do desejo e das práticas da prostituição masculino carioca (Dissertação de mestrado, Universidade Federal Fluminense, Programa de Pós Graduação em Antropologia, Rio de Janeiro, RJ, Brasil)

Bauer, M. W., \& Jovchelovitch, S. (2002). Entrevista narrativa. In M. W. Bauer \& G. Gaskell (Ed.), Pesquisa qualitativa com texto, imagem e som: Um manual prático. Petrópolis, RJ: Vozes.

Bensusan, H. (2006). Observações sobre a política dos desejos: Tentando pensar ao largo dos instintos compulsórios. Revista Estudos Feministas, 14(2), 445-479.

Brah, A. (2006). Diferença, diversidade, diferenciação. Cadernos Pagu, 26, 329-365.

Burck, C. (2005). Comparing qualitative research methodologies for systemic research: The use of grouded theory, discourse and narrative analysis. Journal of Family Therapy, 27(1), 237-262.

Butler, J. (2002). Cuerpos que importan - sobre os límites materiales y discursivos del "sexo". Buenos Aires: Paidós.

Caetano, M. R. V., Silva, P. M., Jr., \& Garay Hernandez, J. (2015). Ninguém nasce homem, torna-se homem: As masculinidades no corpo e o corpo nas práticas curriculares das masculinidades. Revista Periódicus, 2, 8-18.

Cantalice, T. S. T. (2009). Dando um banho de carinho! Os caça-gringas e as interações afetivo-sexuais em contextos de viagem turística (Pipa $R N$ ) (Dissertação de mestrado, Universidade Federal de Pernambuco, Recife, PE, Brasil).

Charmaz, K. (2009). A construção da teoria fundamentada (J. E. Costa, Trans). Porto Alegre, RS: Artmed.

Connell, R. W., \& Messerschmidt, J. W. (2013). Masculinidade hegemônica: Repensando o conceito. Revista Estudos Feministas, 21(1), 241-282.

Flick, U. (2009). Introdução à pesquisa qualitativa (3. ed.). Porto Alegre, RS: Artmed.
Foucault, M. (1987). Vigiar e punir. Petrópolis, RJ: Vozes.

Gregori, M. F. (2003). Relações de violência e erotismo. Cadernos Pagu, (20), 87-120.

Grov, C., Rodríguez-Díaz, C. E., Jovet-Toledo, G. G., \& Parsons, J. T. (2015). Comparing male escorts' sexual behaviour with their last male client versus non-commercial. Culture, Health \& Sexuality: An International Journal for Research, Intervention and Care, 17(2).

Haraway, D. (1995). Saberes localizados: A questão da ciência para o feminismo e o privilégio da perspectiva parcial. Cadernos Pagu, 5(5), 7-41.

Keller, R. (2005). Analysing Discourse: An approach from the Sociology of Knowledge. Forum Qualitative Sozialforschung, 6(3), 1-13.

Kimmel, M.S. (1997). Homofobia, temor, vergüenza y silencio en la identidad masculina. In T. Valdés \& J. Olavarría, Masculinidades (pp. 49-62).

Kirschner, S. R. (2010). Sociocultural subjetctivities. Progress, prospects, problems. Theory \& Psychology, 20(6), 765-780.

Louro, G. L. (2008). Gênero e sexualidade: Pedagogias contemporâneas. Pro-Posições, 19, 2(56), 17-23.

Louro, G. L. (2011) Pedagogias da sexualidade. In G. Louro (Ed.), O corpo educado - Pedagogias da sexualidade. Belo Horizonte, MG: Autêntica.

Madureira, A. F. A., \& Branco, A. M. C. U. A. (2007). Identidades sexuais não-hegemônicas: Processos identitários e estratégias para lidar com o preconceito. Psicologia: Teoria e Pesqui$s a, 23(1), 81-90$.

Medrado, B., \& Lyra, J. (2008). Por uma matriz feminista de gênero para os estudos sobre homens e masculinidades. Revista Estudos Feministas, 16(3), 809-840.

Melo Pedroso, V. A. (2015). Exercício ou exploração? O eterno dilema da sexualidade na prostituição feminina. Derecho y Cambio Social. Recuperado em derechoycambiosocial.com

Nardi, H. C. (2006). Poder sexo e o preço do prazer: Processos de subjetivação e prostituição masculina. In C. Almeida, C. Golim, \& F. Pocahy, Prazer também tem preço: Saúde, prostituição e cidadania. Porto Alegre, RS: Nuances.

Niccolai, L. M., King, E. J., Eritsyan, K. U., Safiullina, L., \& Rusakova, M. M. (2013). 'In 
different situations, in different ways': Male sex work in St. Petersburg, Russia. Culture, Health \& Sexuality, 15(4), 480-493.

Paechter, C. (2003). Masculinities and femininities as communities of practice. Women's Studies International Forum, 26(1), 69-77.

Pelúcio, L. (2014). Traduções e torções ou o que se quer dizer quando dizemos queer no Brasil? Revista Periódicus, 1(1), 68-91.

Perlongher, N. (2008). O negócio do michê (2. ed.). São Paulo, SP: Fundação Perseu Abramo.

Piscitelli, A. (2012). Feminismos y prostitución en Brasil: una lectura a partir de la antropología feminista. Cuadernos de Antropología Social, (36), 11-31.

Piscitelli, A. (2014). Violências e afetos: Intercâmbios sexuais. Cadernos Pagu, 42, 159-199.

Piscitelli, A., \& Simoni, V. (2015). Masculinities in times of uncertainty and change: Introduction. Etnográfica, 19(2).

Pocahy, F. A. (2012). "Vem meu menino, deixa eu causar inveja": Ressignificações de si nas transas do sexo tarifado. Sexualidad, Salud y Sociedad-Revista Latinoamericana, (11), 122-154.

Rios, R. R. (2012). Direitos humanos, direitos sexuais e homossexualidade. Amazônica-Revista de Antropologia, 3(2), 288-298.

Scott, J. (1995). Gênero: Uma categoria útil de análise histórica. Educação e Realidade, 20(2), 71-99.

Toneli, M. J. F., \& Perucchi, J. (2006). Territorialidade homoerótica: Apontamentos para os estudos de gênero. Psicologia \& Sociedade, 18(3), 3947.

Torrão, A., Filho. (2005). Uma questão de gênero: Onde o masculino e o feminino se cruzam. $\mathrm{Ca}$ dernos Pagu, (24), 127-152. doi:10.1590/S010483332005000100007

Viana, N. J. Q. (2010). É tudo psicológico/dinheiro/ pruuuu e fica logo duro! - Desejo, excitação e prazer entre boys de programa com práticas homossexuais em Recife (Dissertação de mestrado, Programa de Pós-graduação em Psicologia, Universidade Federal de Pernambuco, Recife, PE, Brasil).

Viveros-Vigoya, M. (2011). Teorías feministas y estudios sobrevarones y masculinidades: Dilemas y desafíos recientes. La Manzana de la Discordia, 2(4), 25-36.

Welzer-Lang, D. (2001). A construção do masculino: Dominação das mulheres e homofobia. Revista Estudos Feministas, 9(2), 460-482.

Wenger, E. (2001). Comunidades de práctica. Aprendizaje, significado e identidad. Barcelona: Paidós. 